\title{
Urban air pollution and chronic obstructive pulmonary disease: a review
}

\author{
J. Sunyer
}

\begin{abstract}
Urban air pollution and chronic obstructive pulmonary disease: a review. J. Sunyer. (C) ERS Journals Ltd 2001.

ABSTRACT: There is consistency in the findings that relate the acute increases in urban air pollution (mainly the particulate matter) and the short-term health effects (i.e. mortality and hospital admissions) on patients suffering from chronic obstructive pulmonary disease (COPD). Beyond the acute effects, a relevant public health and scientific question is to what extent chronic exposure to air pollution is related with lung function impairment and development of COPD.

The few cross-sectional studies showed an increase of self-reported diagnosis of chronic bronchitis and emphysema, breathlessness and mucus hypersecretion and lower levels of lung function in the more polluted areas. The two cohort studies in children have found a retardation of pulmonary function growth, and the only cohort in adults a faster decline of lung function.

Given the intrinsic limitations of cross-sectional studies to separate the timing between exposure and effects, and the weaknesses of the cohorts (i.e. few areas, short follow-up, only one retest, lack of individual weighting of air pollution measure) there is a need for new prospective studies. These should be performed in a large number of geographical areas and with a long follow-up to asses the impact of long-term air pollution on lung function growth and decline, and on incidence, duration, severity and survival of chronic obstructive pulmonary disease.

Eur Respir J 2001; 17: 1024-1033.
\end{abstract}

Unitat de Recerca Respiratòria i Ambiental, Institut Municipal d'Investigació Médica, Barcelona, Spain.

Correspondence: J. Sunyer, Unitat de Recerca Respiratòria i Ambiental, Institut Municipal d'Investigació Mèdica, Doctor Aiguader 80, E-08003 Barcelona, Spain.

Fax: 34932216448

\section{Keywords: Air pollution}

chronic obstructive pulmonary disease lung function

particulates

Received: June 222000

Accepted after revision November 30 2000

\section{Histological background}

The majority of deaths occurring during the fog episode in London in 1952 involved subjects diagnosed of bronchitis (table 1) [1]. Physicians and public health officers concluded that subjects suffering from cardiorespiratory disease were the most susceptible to the London fog [2]. LAWTHER et al. [3] followed up a series of panels of patients suffering from chronic bronchitis in London during the periods 1959-60, 1964-65 and 1967-68 [3]. Patients recorded daily changes in their symptoms and medication in a diary. Increases in daily air pollution levels, rather than weather, were associated with exacerbation of chronic bronchitis. The association between air pollution and daily symptomatology during the last period was of a lower magnitude than that of the previous periods, coinciding with lower values of black smoke (mean $68 \mu \mathrm{g} \cdot \mathrm{m}^{-3}$ ) and the absence of episodes of high air pollution (i.e. values of sulphur dioxide $>500 \mu \mathrm{g} \cdot \mathrm{m}^{-3}$ ) [3]. During 1968, Carnow et al. [4] conducted two large panel studies in Chicago and found an acute association between a personal pollution index and acute illness (breathlessness, dyspnoea, cough and phlegm) in patients with chronic bronchopulmonary diseases.

Previously during the $1950 \mathrm{~s}$, researchers in the UK had shown that air pollution was not only the cause of sudden exacerbation in patients suffering from chronic obstructive pulmonary disease (COPD), but also that prevalence of chronic bronchitis (CB) and cor pulmonale appeared to be greater in postmen from areas with higher pollution than in postmen from other areas [5]. A later study on the general population reached the same conclusions [6], and a new study on postmen during the 1960s observed reduced levels of lung function in areas with higher air pollution [7]. A higher prevalence of respiratory diseases compatible with COPD in areas with higher air pollution was also observed in the US [8-10] and Poland [11]. In the Netherlands, VAN DER LeNDE et al. [12] investigated the decline in forced expiratory volume in one second (FEV1) using repeated observations in the same subjects, and found that living in highly polluted areas had effects independent of smoking, on a faster

Table 1.-Cause specific mortality during the London fog of December $\left(6^{\text {th }}-13^{\text {th }}\right) 1952$

\begin{tabular}{lcc}
\hline Cause & Excess n (\%) & RR (95\% CI) \\
\hline Bronchitis & $628(41)$ & $9.3(8.6-10)$ \\
Other respiratory & $188(12)$ & $4.4(3.8-5.0)$ \\
Coronary & $163(11)$ & $2.4(2.0-2.8)$ \\
Other heart & $272(18)$ & $1.6(1.4-1.8)$ \\
Rest & $288(19)$ & $1.5(1.3-1.7)$ \\
\hline
\end{tabular}

Adapted from [2]. Excess (number of excess deaths) and relative risk (RR) versus previous week. CI: confidence interval. 
decline in FEV1. However, studies conducted during the 1970s in areas with low levels of air pollution did not observe an increase of respiratory symptoms or diseases associated with air pollution [13-14], and there was a widespread belief that air pollution levels achieved after the Clean Air Act programmes guaranteed health.

The present paper is a review of the epidemiological research conducted during the last $20 \mathrm{yrs}$ on the role of air pollution in the exacerbation of a pre-existing COPD (i.e. the short-term effect) and also on the causation of COPD (i.e. the long-term effect) with lower levels of particles and gases, but with different air pollution mixtures due to a reduction in the use of coal, the increase of traffic, and the control of industrial emissions, than in earlier times. Sudden functional, biological and clinical changes after air pollution exposures have been extensively studied in experiments. The study of chronic effects of air pollution is methodologically more complex and can only be carried out through epidemiological studies. Toxicological research and chamber studies are not addressed in this review.

\section{Definition of chronic obstructive pulmonary disease}

The definition of COPD is still an open issue [15] which has been approached from a clinical perspective where the dominant needs are diagnosis and treatment [16]. However, a single definition may not serve all purposes equally well. From an epidemiological perspective, the definition needs to be translated into operative criteria. Thus, the use of quantitative criterion, such as the FEV1, provides a valuable intermediate phenotype.

In the studies on the short-term effects of air pollution, case definition was based on doctor diagnosis in death certificates and clinical records, as well as in self-reported daily variations of symptoms and treatment in patients with a diagnosis of COPD based on clinical and spirometric criteria. Mortality due to COPD was based on diagnosis labels in death certificates. Studies on admissions rely on diagnosis of exacerbations of the disease. Although acute exacerbations are considered to be the most common cause of hospital admission in COPD patients, there is no wellestablished definition, and the studies have used the diagnosis labelling stated in medical records.

The natural history of COPD is characterized by a progressive, irreversible decline in lung function. In normal conditions, lung function achieves maximum values at the age of 20-25, followed by a slow, progressive decline due to ageing. The earliest step of COPD may involve either suboptimal development of lung function during childhood or an accelerated decline $[17,18]$. The appearance of the clinical disease over the years is a result of the level of initial lung function (the maximum value attained during childhood and adolescence) and the decline after youth [17, 18]. Thus, when symptoms appear, most of the volume and flow capacity has already been lost $[17,18]$. After years of suffering dyspnoea and disability, many patients with COPD die as a consequence of the disease [19]. Although most smokers with COPD experience $\mathrm{CB}$, as a definition for chronic hypersecretion at an early stage, both entities may develop independently, and mucus hypersecretion and decreased FEV1 were seen as different entities [17, 19]. Most studies have shown either a small or no association of mucus hypersecretion and respiratory infection with the decline of FEV1 [19, 20]. Among the intermediate symptoms of COPD, breathlessness, in contrast to chronic productive cough, was the symptom associated with the largest loss of lung function in studies on the natural history of COPD [19-21].

Studies on the chronic effects of air pollution have been carried out at different stages of the long natural history of COPD. Given that symptoms appeared in a latter phase of the disease, this report has selected only studies of symptoms during adulthood. In addition, since the distinction between asthma and COPD remains a major difficulty $[15,16]$, this review has excluded studies on asthmatics with COPD. By contrast, it has included studies on lung function at all ages. FEV1 showed a strong within-individual tracking during life [22] and studies in children may indicate the potential effects on lung function growth, which could be associated with COPD later in the elderly.

\section{Short-term effect of air pollution on patients with chronic obstructive pulmonary disease}

The short-term patterns of association between air pollution increases and increases in health events in patients suffering from COPD has been investigated using aggregated time series studies on respiratory mortality or COPD hospital admissions in the total population (i.e. studies measuring daily variations in the number of health events in a city in relation to daily variations in air pollutants and confounding variables, such as temperature) and in individual studies, such as in case-crossover studies in cohorts of COPD patients as well as in panel studies (i.e. studies following daily variations in symptoms and other markers of exacerbation in a group of patients with COPD in relation to daily variations of air pollution at the city level).

Time-series studies on mortality and hospital admissions

The pattern of excess death seen in the Philadelphia time-series study on mortality and air pollution at the end of the 1970s parallels the pattern seen in London in 1952. The increased risk of dying due to COPD associated with air particles among the general population was triple the increase in all-cause mortality [23]. In addition, respiratory conditions increased substantially as contributing causes of death among cardiovascular deaths occurring in days with high pollution levels [24]. The magnitude of this increase could not be explained by a bias due to miscoding of death registers. Similarly, in time-series multicentre studies on mortality conducted in Europe in more recent years, such as the Air Pollution Health Effects 
Approach (APHEA) study, the greatest increase in the association between mortality and air pollution (mainly particulates, but also sulphur dioxide) was observed for deaths due to respiratory conditions (relative risk $(\mathrm{RR})=1.04 ; 1.2-1.07$ for black smoke). The RR for mortality due to cardiac diseases was lower $(\mathrm{RR}=1.02$, $1.01-1.04$ ) [25-27]. Studies on mortality did not assess the specific mortality due to COPD (given the small daily values in any city) and furnish information for all respiratory diseases.

Studies on daily admissions in emergency rooms and hospital admissions were specific for COPD. Studies conducted during the 1980s and 1990s in different cities in Europe, USA and Australia have consistently observed that admissions due to COPD increased on days with high pollution values (table 2) [28-34]. The results for particles are less consistent than those for ozone. The association for particles was smaller in Europe, which may be explained by the inclusion of individuals less susceptible (mainly due to lower age), or by the chemical nature of particles and differences in their measurement [28]. The relative risk of admission due to COPD was much higher than the relative risk for a cardiac cause, which coincides with studies on daily mortality $[32,35,36]$.

In addition, a study performed in a cohort of patients diagnosed with COPD, showed that the relative risk of dying due to particles was much higher among subjects with COPD than in studies conducted with the total population [37]. The association between black smoke and the risk of dying due to respiratory causes $(\mathrm{RR}=1.18,1.02-1.36)$ was higher than for cardiovascular causes $(\mathrm{RR}=1.08,0.92-1.36)$ [37]. Patients with a more severe COPD had a higher risk of dying in relation to particle levels [37].

\section{Panel studies of patients with chronic obstructive pulmonary disease}

Panel studies have rarely been conducted among COPD patients, since sudden changes in the degree of airway obstruction only occurred in some of the patients with COPD. Nevertheless, there have been some attempts to relate daily variations in lung function in COPD patients with air pollution. POPE and KANNER [38] observed that FEV1 was associated with the level of particles with a $50 \%$ cut-off

Table 2. - Per cent increase of Emergency Room admissions due to chronic obstructive pulmonary diseases for each increase in $50 \mu \mathrm{g} \cdot \mathrm{m}^{-3}$ (95\% confidence interval) of air pollutants

\begin{tabular}{lcc}
\hline City & Particles & Ozone \\
\hline APHEA* [28] & $3.5(1.0-6.0)$ & $4.3(1.1-6.5)$ \\
Birmingham, AL, USA [29] & $12(3.5-22)$ & $3.0(-2.5-10)$ \\
Detroit, MI, USA [30] & $20(9.0-32)$ & $6.0(1.5-10)$ \\
Spokane, WA, USA [33] & $17(7.1-28)$ & $13(1.1-25)$ \\
Minneapolis, MN, USA [31] & $25(10-53)$ & $3.0(-3.9-7.0)$ \\
Sydney, Australia [34] & $5.1(-0.6-10)$ & $1.5(-7.6-12)$ \\
\hline
\end{tabular}

*: Amsterdam, Barcelona, London, Milan, Paris, Rotterdam Adapted from [28]. aerodynamic diameter of $10 \mu \mathrm{m}$ (PM10) on the day of testing in a study conducted on 624 smokers with mildto-moderate COPD who were tested twice, 10-90 days apart, in Salt Lake City (USA) during the years 1987-1989. Subjects retested on cleaner days had better lung function values than in the previous test, while subjects retested on more polluted days had a relative decrease, although air pollution (PM10 levels) only explained a small fraction $(2-3 \%)$ of the FEV1 variation, independent of the degree of bronchial reactivity. Transient effects of air pollution on pulmonary function may not only occur in patients with COPD, since they had previously been observed among healthy children after acute air pollution episodes [39-42]. However, these small transient effects may not be detected in panel studies under background air pollution levels. There is only one study which exclusively includes subjects with COPD [43]. In Christchuch (New Zealand), a panel of 55 subjects with COPD was followed for 3 months in 1994 [43]. A rise in the interquartile range of $\mathrm{PM} 10$, of $35 \mu \mathrm{g} \cdot \mathrm{m}^{-3}$, was associated with an increase in night-time chest symptoms ( $\mathrm{RR}=1.38,1.07-1.78)$ [44]. An increase of nitrogen dioxide $\left(\mathrm{NO}_{2}\right)$ was associated with increased relieved inhaler use $(\mathrm{RR}=1.42,1.13-1.72)$. There was no evidence of any effects of air pollution on peak expiratory flow. The other panel studies [44, 45] included patients with asthma. In a panel study conducted in the UK, only 10 of the 75 subjects included had COPD, whereas the rest were asthmatic [44]. A large panel study in 489 adults $(50-70$ yrs of age) was conducted in the Netherlands during the years 1992-1993 [45]. Subjects suffered from chronic obstructive respiratory symptoms (either wheezing/ shortness of breath or cough/phlegm) and were selected from a cross-sectional study in the general population. Inclusion of subjects in the panel was not based on diagnosis of COPD, but rather on symptoms of asthma and or chronic bronchitis $(43 \%$ of them reported attacks of shortness of breath and $8 \%$ reported attacks of asthma, whereas chronic phlegm was reported for $40 \%$ of subjects).

Overall, panel studies conducted during recent decades fail to separate the asthma phenotype from the COPD phenotype, although it is complex among the elderly. Besides, the indicator of sudden effects among COPD patient could not be based on sudden lung function changes, due to the insensitivity of these variables among subjects with COPD. Nevertheless, the study in Christchuch (New Zealand) [43], with the best characterization of the COPD phenotype, suggests that, even at current levels of air pollution, COPD patients have more symptoms during days with increased levels of pollutants, coinciding with the findings from time-series studies.

\section{Long-term effects of urban air pollution on development of chronic obstructive pulmonary disease}

Beyond the effect of air pollution on the exacerbation (i.e. aggravation) of the disease among subjects suffering from COPD, a relevant question is to what extent air pollution is a risk factor for new cases of 
COPD. Is the chronic exposure to air pollution related to the incidence of COPD? Long-term effects of air pollution have been evaluated largely by cross-sectional comparisons of the prevalence of COPD among subjects who lived in environments with varying profiles of ambient air pollution. Prevalence is a good indicator of incidence in a chronic and nonreversible disease, such as COPD, in the absence of migration, and if duration of the disease is similar in all the study areas. Cross-sectional studies have also compared the level of lung function among subjects from different areas. Besides the cross-sectional studies, there have been few successful attempts to measure the effect of air pollution on lung function growth and decline using cohort studies in the general population. In addition, there have been three prospective cohort studies in the USA [46-49] on the relationship between ambient concentrations in the past and mortality in the general population. Specific mortality for COPD was not measured, but two of the studies reported mortality for cardiopulmonary conditions $[46,47]$ and a third for nonmalignant respiratory diseases [48, 49].

\section{Mortality}

The Harvard six-cities study followed a cohort of 8,111 adults from between 1974 and 1977 to 1991 in 6 cities of the USA (Boston, MA; Knoxville, TN; Portage, WI; St. Louis, MO; Steubenville, OH, Topeka, KS) and found that adjusted mortality due to cardiopulmonary conditions appeared to increase in areas with the highest past levels of fine particles and sulphates, independently of smoking, occupation and social class [46]. A larger study was that of the American Cancer Society (ACS) which followed 552,138 adults from 151 areas during 7 yrs starting in 1982 , and provided results on particles with a $50 \%$ cutoff aerodynamic diameter of $2.5 \mu \mathrm{m}$ (PM2.5) (only for 50 areas) and sulphates, with the higher relative increase observed for cardiopulmonary causes of death in cities with high levels, in comparison with the low pollution cities [47]. The third study was conducted in 6,338 nonsmokers of the Adventist Health Study of Smog in California (AHSMOG) and did not find an association between total suspended particles (TSP) and all causes of death combined, using data collected from 1977-1987 [48]. However, the follow-up of this third cohort up to 1992, using 348 centroid monitoring stations of PM10 throughout California found an increase for PM10, instead of TSP, in deaths due to nonmalignant respiratory conditions (both as a main cause and as a contributory cause) in males (the association in females was not statistically significant, and did not occur for cardiopulmonary diseases) [49]. In addition to the American cohorts, there are preliminary results of the long-term French study Pollution Atmospherique et Affections Respiratoires Croniques (PARC) that have suggested that survival was lower in areas with high levels of sulphur dioxide $\left(\mathrm{SO}_{2}\right)$ during the period 1974-1976 [50].

By adjusting analysis for individual characteristics of subjects (i.e. smoking, occupation, education or migration) the cohort studies showed that the association with mortality was unlikely to be explained by these variables. A higher mortality rate in areas with higher air pollution could be due to either a higher prevalence of the disease, and/or a higher severity of the disease in the most polluted areas. The major limitations of these studies for the study of COPD, however, are the lack of specificity of the cause of death (i.e. the impossibility to tease out the effect on COPD from that on other respiratory deaths or cardiac deaths) and the validity of the diagnosis of the death certificates [51].

\section{Symptoms}

In adults, cross-sectional studies on prevalence of symptoms are rare. Only AHSMOG in California [52] and the Swiss Study on Air Pollution and Lung Diseases in Adults (SAPALDIA) in Switzerland [53] were designed to measure the health effects of air pollution. Other studies, like the National Health and Nutrition Examination Survey (NHANES) in the USA [54], the US National Health Interview Study [55], as well as the Swedish cities participating in the European Community Respiratory Health Study (ECRHS) [56] did a more extended interview, not initially designed for the study of air pollution effects. All studies consistently found a higher prevalence of symptoms of hypersecretion, breathlessness, or diagnoses of $\mathrm{CB}$, emphysema or COPD in areas with higher particulate air pollution, and some studies also found an association with levels of $\mathrm{SO}_{2}$. In Switzerland and Sweden, an association of prevalence of symptoms with $\mathrm{NO}_{2}$ was also observed [53, 57]. Among the studies reviewed, some used diagnosis of $\mathrm{CB}$ or emphysema $[52,54,55]$, while others measured symptoms [52, 53, $56,57]$. In the SAPALDIA study [53], the strongest association was obtained with breathlessness, the symptom associated with the largest loss of lung function $[19,20]$.

\section{Lung function level}

Studies on lung function in children (table 3) are of value since they indicate the potential effects on lung function growth. DocKery et al. [58] in the Harvard six-cities study, investigated 5,422 children from $10-12$ yrs old during 1980-1981, and did not observe any association with pulmonary function. SCHWARTZ [59] argues that the explanation for the lack of association was the low number of cities with high levels of particles, given his results from the study based on NHANES-II (which included children and young people) of a threshold level of the effect on lung function $\left(85 \mu \mathrm{g} \cdot \mathrm{m}^{-3}\right.$ of particles) using a higher number of cities. There have recently been reports from three big studies in the USA and Canada [60-62]. All these studies observed lower levels of forced vital capacity (FVC) and FEV1 in children whose lifelong residency had been in areas with higher particulate pollution. In the study of Southern California [62], the effects were larger in young females who spent more time outdoors.

There are few cross-sectional studies on lung 
Table 3. - Summary of the cross-sectional and cohort epidemiological studies on lung function and air pollution

\begin{tabular}{|c|c|c|c|c|c|}
\hline Author reference & Location & Age & Sites & Lung function measure & Effect \\
\hline \multirow{2}{*}{\multicolumn{6}{|c|}{$\begin{array}{l}\text { CROSS-SECTIONAL } \\
\text { Children }\end{array}$}} \\
\hline & & & & & \\
\hline Dockery [58] & USA & $10-12$ & 6 & $\begin{array}{l}\text { FVC } \\
\text { FEV1 }\end{array}$ & No association \\
\hline Schwartz [59] & USA & $6-24$ & 64 & $\begin{array}{l}\text { FEV25-75 } \\
\text { FVC } \\
\text { FEV1 }\end{array}$ & $-6 \%$ per $100 \mu \mathrm{g} \cdot \mathrm{m}^{-3} \mathrm{TSP}$ \\
\hline Stern [60] & Canada & $8-10$ & $10^{*}$ & $\begin{array}{l}\text { FVC } \\
\text { FEV1 }\end{array}$ & $\begin{array}{l}-1.7 \% \text { per } 6 \mu \mathrm{g} \cdot \mathrm{m}^{-3} \text { of sulphates } \\
-1.3 \% \text { per } 6 \mu \mathrm{g} \cdot \mathrm{m}^{-3} \text { of sulphates }\end{array}$ \\
\hline Raizenne [61] & USA and Canada & $8-12$ & $24^{*}$ & $\begin{array}{l}\text { FVC } \\
\text { FEV1 }\end{array}$ & $\begin{array}{l}-3.25 \% \text { per } 52 \mathrm{nmol} \cdot \mathrm{m}^{-3} \text { acidity } \\
-3.1 \% \text { per } 52 \mathrm{nmol} \cdot \mathrm{m}^{-3} \text { acidity }\end{array}$ \\
\hline Peters [62] & Southern California & $9-16$ & 12 & $\begin{array}{l}\text { FVC } \\
\text { FEV1 }\end{array}$ & $\begin{array}{l}31.8 \mathrm{~mL} \text { per } 15 \mu \mathrm{g} \cdot \mathrm{m}^{-3} \text { of } \mathrm{PM} 2.5 \\
19.6 \mathrm{~mL} \text { per } 15 \mu \mathrm{g} \cdot \mathrm{m}^{-3} \text { of } \mathrm{PM} 2.5\end{array}$ \\
\hline \multicolumn{6}{|r|}{ 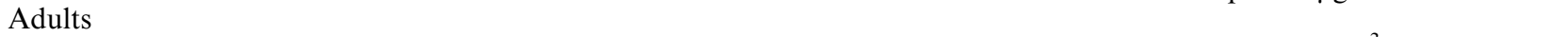 } \\
\hline Ackerman [63] & Switzerland & $18-60$ & 8 & FVC & $-3.24 \%$ per $10 \mu \mathrm{g} \cdot \mathrm{m}^{-3}$ of $\mathrm{PM} 10$ \\
\hline Chestnut [64] & USA & $25-75$ & 90 & FVC & $-2.25 \%$ per $34 \mu \mathrm{g} \cdot \mathrm{m}^{-3} \mathrm{TSP}$ \\
\hline Abbey [66] & California & $43-80$ & 348 & FEV1 & $\begin{array}{l}-7.2 \% \text { per } 54 \text { days } \cdot \text { year }^{-1} \text { with } \\
\text { PM10 }>100 \mu \mathrm{g} \cdot \mathrm{m}^{-3}\end{array}$ \\
\hline $\begin{array}{c}\text { Xu [67] } \\
\text { COHORT STUDIES }\end{array}$ & Xina & $40-69$ & 3 & FEV1 & -131.4 mL doubling TSP \\
\hline Frisher [69] & Austria & 7 & 8 & $\Delta \mathrm{FEF} 1$ & $-0.029 \mathrm{~mL} \cdot$ day $^{-1}$ per ppb of $\mathrm{O}_{3}$ \\
\hline Jedrychowski [71] & Poland & $9-11$ & $15^{*}$ & $\Delta \mathrm{FEV} 1$ & $\begin{array}{l}\text { odds ratio }=2.1 \text { and } 1.5 \text { in male and } \\
\text { female children, respectively, } \\
\text { for }-0.18 \mathrm{~L} / 2 \mathrm{yrs} \text { between high } \\
\text { and low pollution areas }\end{array}$ \\
\hline Detels [72] & Los Angeles & $25-59$ & 3 & $\triangle \mathrm{FEV}_{1}$ & $\begin{array}{l}-23.6 \text { and }-9.6 \mathrm{~mL} \cdot \mathrm{yr}^{-1} \text { in males } \\
\text { and females between Long } \\
\text { Beach and Lancaster }\end{array}$ \\
\hline
\end{tabular}

*: Data was analysed comparing two groups of exposure (low versus high). TSP: total suspended particles; PM10: particles less than $10 \mu \mathrm{m}$. FVC: forced vital capacity; FEV1: forced expiratory volume in one second; FEV25-75: forced mid-expiratory volume; $\triangle \mathrm{FEV} 1$ : change in FEV1.

function levels and air pollution in adults (table 3 ). The SAPALDIA study was conducted in Switzerland [63] during the years 1991 - 1993 in 9,651 subjects of eight communities with low levels of air pollution (mean $\left.\mathrm{PM} 10=21 \mu \mathrm{g} \cdot \mathrm{m}^{-3}\right)$. This study measured most of the potential confounding variables, but the variation in air pollution levels was less than in the study in the USA using NHANES-I data [64]. In the Swiss study, the authors were able to measure personal levels of $\mathrm{NO}_{2}$, in addition to the city-average levels of particles. They found that home outdoor measurements of $\mathrm{NO}_{2}$ and personal measurements of $\mathrm{NO}_{2}$ were related with a lower FVC $\left(-0.59 \%\right.$ and $-0.74 \%$ per $10 \mu \mathrm{g} \cdot \mathrm{m}^{-3}$, respectively) [65]. The authors were able to exclude people who had recently moved, controlling in part the potential immigration bias due to the cross-sectional nature of the design. The small number of areas in SAPALDIA did not allow the association with lung function to be separated according to the different pollutants. Another study on the levels of lung function was the AHSMOG cohort that assigned personal air pollution during the period 1977-1993 based on distance of the residence from 348 monitoring stations, and measured lung function in 1993, in 1,391 nonsmokers always living in the same place [66]. Men with a higher exposure to PM10 had lower levels of FEV1. As observed for the association within AHSMOG on mortality, there were sex inconsistencies in the association with lung function that were difficult to explain biologically (the lower values of FEV1 in relation to PM10 levels were only observed for males, and there was a stronger association with respiratory mortality in males). A different intensity of exposure in females or a residual confounding by indoor occupation was discussed by the authors as explanations of these differences. Given the prospective nature of this study, it avoided problems of migration typical of cross-sectional studies. However, it could not measure lung function decline since only a single test was performed. Finally, there was a study in three areas highly polluted from coal combustion in China [67]. Part of the effect could be attributed to indoor pollution, although authors tried to adjust for this factor.

\section{Lung function growth in children and adolescents}

Among the studies using repeated measures of lung function in each individual, studies on failure to maintain the predicted lung function growth curve during pre-adolescence are easier to conduct than studies in adulthood, given the lack of smoking. Three cohort studies have been conducted on lung function growth, although one of them was conducted at the end of $1970 \mathrm{~s}$ and investigated a point-source of an industrial pollution [68] rather than the urban pollution.

DoDGE et al. [68] performed lung function measurements in 1979 and 1982, on two cohorts of 193 children 
aged 9-11 from two areas located in the vicinity of a smelter in Arizona (USA), one downwind from the smelter and highly polluted, and the other as a control. They did not find decreased lung function growth to be associated with high air pollution, although children in the more polluted area reported more cough.

Two big studies assessing the effect of ambient air pollution on lung function growth in pre-adolescent children have recently been carried out in Europe (table 3). The first of these prospective studies was carried out in nine areas of Austria [69] and in two areas of Germany [70], selected according to ozone exposure. Of the 1,150 7-yr-old children included, 92\% completed all the tests. Individual ozone exposure was calculated weighting the mean of the monitoring site of the village with the time spent by each child in the village. The range of ozone exposure between the highest and lowest values differ by a factor of 2 (range of ozone $=18-40$ part per billion (ppb)). Lung function was measured 6 times from 1994-1996. Exposure to summertime ozone, and to a less extent to wintertime ozone, was negatively associated with changes in FVC, FEV1 and mean maximal expiratory flow (MEF50). For a child living in an area with levels of ozone of $10 \mathrm{ppb}$ higher than for a child from another community, the reduction in FVC growth was $48(95 \% \mathrm{CI}=21-75) \mathrm{mL}$. The authors failed to find a consistent association with other pollutants, but fine particles (sulphates and acidity particles that usually rise together with ozone) were not measured.

The second study was conducted among adolescents in Krakow (Poland) [71]. Air pollution (particles and $\mathrm{SO}_{2}$ ) was measured in 17 monitoring stations and values were attributed to those residents living within a radius of $0.5 \mathrm{~km}$ of the station. Air pollution exposure was classified only in two levels (low and high). The lung function gain was measured by FVC and FEV1 and data was obtained on social class and exposure to indoor pollution (environmental tobacco smoking (ETS), type of heating and molds). Nine-yr-old children $(\mathrm{n}=1,165)$ were recruited and $89 \%$ were followed for 2 yrs. The baseline study was carried out in 1995 and repeated in 1997. Male children who lived in the more polluted area had higher FVC and FEV1 values at baseline, but both male and female children who lived in these areas showed lower lung function growth rates than children who lived in less polluted areas, after 2 yrs. The effect due to air pollution was not explained by the other studied variables. The proportion of subjects with a lower lung function growth (defined as $-0.18 \mathrm{~L}$ and $-0.19 \mathrm{~L}$ of FEV 1 in male and female children, respectively, over 2 yrs, based on the lowest quintile of the distribution of spirometric values) was 2 times and 1.5 times higher in male and female children from the polluted area, respectively, in comparison with children of the lesser polluted areas. Levels in the high air pollution areas were moderate at the time of the study (average $\mathrm{SO}_{2}=44 \mu \mathrm{g} \cdot \mathrm{m}^{-3}$, and average of TSP $\left.=53 \mu \mathrm{g} \cdot \mathrm{m}^{-3}\right)$.

It is difficult to conclude from these studies that a certain pollutant is related to the slowing of lung function development, due to the poor characterization of the atmosphere components and the problem of comparing between few levels of exposure (i.e. high and low exposures). However, the prospective nature of both studies, and the effort to measure the main covariables, suggests that urban air is involved in lung function development, although in the case of Austria, levels of air pollution are low in comparison with other European areas. Due to the age under study and the short follow-up, these studies could not assess whether the slowing in growth observed would result in a definitive lower maximum FEV1 attained at youth, or whether the decreases were only transient.

\section{Lung function decline in adults}

There is only one cohort study assessing the effect of COPD on the decline of FEV1 (table 3). The University of California at Los Angeles Chronic Obstructive Respiratory Disease (UCLA-CORD) study followed changes in lung function over time in several cohorts of smokers and nonsmokers residing in areas of Southern California, chronically exposed to different levels and types of air pollution [72, 73]. The three areas were: Lancaster, with moderate levels of photochemical oxidants and low levels of particles; Glendora, with high levels of photochemical oxidants; and Long Beach with high levels of particles, nitrogen oxides and sulphates. Eligible residents (aged 25-59) were tested twice, once in 1973-78 and once in 1978-82. Around $50 \%$ of the subjects were retested (around 800 per area), and there were no significant differences in baseline characteristics between participants and nonparticipants in the retest. Equipment and staff in the retesting were almost the same as in the first test. Mean declines of FEV1 in males were significantly lower in Lancaster, as well as in Glendora compared with Long Beach, in each category of smoking. In females, similar findings were obtained for never-smokers, but no differences by area were observed in smokers. In males, living in Long Beach in comparison to living in Lancaster explained a substantial decline in FEV1 with about $70 \%$ of the decline being due to current smoking of 1 pack $\cdot$ day $^{-1}$ of cigarettes. Results, then, suggest that heavy air pollution may lead to the development of COPD and that chronic exposure to particulates, sulphates and nitrogen oxides (Long Beach) may be more damaging than levels of ozone (Glendora). Major limitations of the study were: the small number of areas studied, the potential for a socioeconomic self-selection by area, the low proportion of subjects retested, and the lack of control for season and field worker between the two spirometries. Among these limitations, the high proportion lost to follow-up, probably differential in relation to lung function by area, creates a major problem for the interpretation of the findings.

\section{Discussion}

There is consistency in the findings that relate the acute increases in urban air pollution and the shortterm health effects on patients suffering from COPD. Particulate air pollution has been related to increases in daily mortality in general population mainly due to respiratory causes, to increased mortality in patients 
with COPD, and to higher rates of hospitalization or admission to emergency departments due to COPD on days with elevated pollution. Associations with pollutants other than particles are less consistent. Both in studies with mortality and with admissions, the association with respiratory causes, and specifically with COPD, were higher than that for cardiac causes. Quantification of the association between air pollution levels and exacerbation of COPD, however, is unclear. Differences in the strength of the effects between the studies are attributed to differences in the susceptibility of the study subjects (i.e. the more severe COPD patients are those with a higher susceptibility in relation to short-term exposures of air pollution [37]), and also to differences in air pollution mixtures and environmental measurement between the locations [28].

In addition to the short-term effects on individuals with COPD, a relevant public health and scientific question is "to what extend chronic exposure to air pollution is related to lung function impairment and development of COPD". It is unlikely that the acute effects on exacerbation would reflect an association of air pollution with the development of the disease, since the influence of acute exacerbation on the progression of COPD has not been established [74]. However, the increase of self-reported diagnosis of $\mathrm{CB}$ or emphysema, both in the American NHANES study [52] and in the AHSMOG study [51], in addition to the increased prevalence of breathlessness and mucus hypersecretion in the SAPALDIA study [53], and the lower lung function parameters in cross-sectional studies [59-65], suggests that air pollution is related to an increased prevalence of COPD, mainly due to a higher incidence of the disease and an impairment of lung function, coinciding with the findings of the few cohort studies in children and adults [69-73]. These cohort studies have found a retardation of pulmonary function growth and a faster decline, which would result in the appearance of the clinical disease over the years. Nevertheless, this global picture has to be considered in the light of the limitations of the studies.

The study of chronic effects poses difficult problems to epidemiology. Cross-sectional studies provide a shortcut to understanding these long-term effects. But the simplification of the temporal associations imposed by the cross-sectional design implies a series of limitations [75]. One problem is that in a cross-sectional study, cases with long duration or mild development of the disease are over-represented, while those with fast development are under-represented [76]. If air pollution were to produce both an increase of the incidence and an anticipation of death, the association observed in a cross-sectional study would be attenuated. A second problem involves changes of exposure occurring in relation to the disease. If subjects with a faster decline, or with established clinical disease, migrate to less polluted areas, the association would also be attenuated. In the cross-sectional analysis of the AHSMOG and SAPALDIA studies, exposure was defined for each individual using residential history, which diminished the potential for this bias A third problem, also common to cohort studies, is self-selection of individuals prior to the beginning of the study, due to different residences according to health and exposure because of differences in socioeconomical factors (usually, poor people live in the more polluted areas without possibility of migration). Thus, a problem common to all these studies comparing different geographical areas, is the lack of adjustment for contextual (aggregated) variables. Adjustment for social conditions and occupation at the individual level, but also at the aggregated level, is required [77]. Another problem is the nature of past exposures given the long lead time between exposure and appearance of disease in COPD. Air pollution exposure has changed during the second half of the century and adults with COPD today had a different air pollution exposure when they were children, which incorporates complexities that could only be tackled with cohort studies from childhood, such as in the six-cities study [46]. A final weakness of cross-sectional studies is the inability to measure incidence or remission of symptoms and changes in lung function. Prevalence of symptoms or lung function level could only reflect a short-term effect. AHSMOG and SAPALDIA studies have measured historical symptoms, although recall in the questionnaires is imperfect.

Results from the reported cohort studies on lung function changes are coincident with the results from cross-sectional studies, suggesting that air pollution caused both a retardation of lung function growth and an acceleration of lung function decline [68, 71, 72]. A problem of these cohort studies is the small number of areas studied, which limit their power to separate the effects of pollutants, and to control for contextual variables, such as the socioeconomic conditions. A second problem is the short time of follow-up, particularly in the studies in children that preclude assessing whether changes are transient or permanent. A third problem in the studies in Poland [71] and UCLA-CORD [72], is that subjects were only retest once, which precludes the control of the possible impact of air pollution levels on the day of testing [38]. Furthermore, only the Austrian study [69] performed an individual weighting of the area air pollution averages to build up an individual measure for each participant. Individual time-pattern characteristics could have introduced a misclassification of the exposure in the other studies. This type of error, could produce a nondifferential bias, and thus a conservative estimation of the effect, although under some exceptional circumstances this type of error may result in an overestimation of the association [78]. Another problem, as occurred in cross-sectional studies, could have been self-selection of the subject's residence by disease characteristics. This type of selfselection may explain in part why the baseline lung function of subjects living in the most polluted areas in Krakow [70] and in UCLA-CORD study [71] were higher than among people in the less polluted areas. If frail people tend to live in the cleaner areas, this type of bias would result in conservative estimates. Another explanation of the paradoxical baseline lung function values in the UCLA-CORD study could have been a differential loss to follow-up of participants by areas. Thus, in the UCLA-CORD study [73], a problem was the important number of individuals lost to follow-up, since the variations in baseline lung function between 
the three areas differed only between those tested once and those retested [72]. Although the authors adjusted for baseline FEV1, a selection bias could not be excluded, since the relation between decline in FEV1 and participation was unknown. Overall, although cohort studies were more robust than cross-sectional studies for aetiological research [74, 75], the weaknesses of these cohort studies do not allow conclusive estimates of the role of air pollution on lung function growth and decline, or on the incidence of symptoms, to be obtained.

At present, epidemiological evidence does not allow observed health effects to be attributed to a single pollutant. The Austrian study signals ozone as the major culprit. However, the authors did not have daily data on fine particles. In the UCLA-CORD study, the greatest decline was observed in the area with high particulate values, rather than the area with high ozone values. In Krakow, pollution was measured by total particulate matter and $\mathrm{SO}_{2}$. Most of the cross-sectional studies found an association with PM10 and sulphates (table 3), but also with $\mathrm{SO}_{2}[60,66]$ and $\mathrm{NO}_{2}$ [63]. There is a need for studies with a larger number of areas, in order to discern the effect of the different ambient air pollutants and evaluate potential interactions. The levels of air pollution in some of these studies are rather low. This is the case for the studies in Switzerland, suggesting that effects of air pollution on COPD may occur almost everywhere.

An intriguing finding of some of these studies is the sex difference of the effects. Thus, in the AHSMOG study, most of the associations with mortality and lung function were only observed in males. Similarly, in the study in Krakow in children, and in the UCLA-CORD study in adulthood, the association with lung function growth and decline were stronger in males. Reasons for this discrepancy lay in differences between male and female exposures in the AHSMOG study [48, 66], or in different nonresponse bias by sex in the UCLA-CORD study [73]. However, given the repetition of this finding in three of the studies, it needs to be investigated in further studies, and requires a biological explanation if it is confirmed.

Overall, epidemiological studies on the short-term effects of air pollution have consistently shown that COPD patients are susceptible to the acute effects of air pollution, and that COPD explained an important part of the total number of deaths attributed to air pollution. In contrast, study of the chronic effects of air pollution in COPD is incomplete. Cross-sectional studies have been carried out in more extended areas and with a better measurement of exposure than cohort studies, but the intrinsic weaknesses of cross-sectional studies for aetiological research preclude attaining definitive and quantitative estimates of the long-term effect of air pollution on COPD. KunZLI et al. [79] have calculated, based on the data provided by the cross-sectional SAPALDIA study, that for an increase of $10 \mu \mathrm{g} \cdot \mathrm{m}^{-3}$ in the annual mean of PM10, the percentage of subjects with an FVC $<70 \%$ predicted would increase from $5 \%$ to $8 \%$.

However, given the limitation of cross-sectional studies, and the discussed weaknesses in the few cohorts followed-up, there is a need for appropriate methodological assessment of the long-term impact of urban air pollution on lung function growth and decline, on incidence, duration and severity of chronic obstructive pulmonary disease, as well as on survival. Thus, prospective studies in a larger number of geographical areas and with a longer follow-up are needed to confirm these important impacts, to disentangle the associations between pollutants, to control for contextual variables, to evaluate the differences between sexes, and to evaluate the degree of reversibility of the findings obtained in studies on lung growth.

\footnotetext{
Acknowledgements. The author is grateful to J.M Antó and J. Garcia-Aymerich for their helpful comments on the manuscript and to D. Mcfarlane and G. Perelló for their help in editing.
}

\section{References}

1. Logan WPD. Mortality in the London fog incident. Lancet 1953; 1: 336-338.

2. Ministry of Health. Mortality and morbidity during the London fog of December 1952. London, HMSO, 1954.

3. Lawther PF, Waller RE, Henderson M. Air pollution and exacerbation of bronchitis. Thorax 1970; 25: $525-$ 539 .

4. Carnow BW, Lepper MH, Shekelle RB, et al. Chicago air pollution study; $\mathrm{SO}_{2}$ levels and acute illness in patients with chronic bronchopulmonary disease. Arch Environ Health 1969; 18: $768-776$.

5. Fairbairn AS, Reid DD. Air pollution and other local factors in respiratory disease. Brit J Prev Soc Med 1958; 12: 94-103.

6. Lambert PM, Reid DD. Smoking, air pollution and bronchitis in Britain. Lancet 1970; 1: 853-57.

7. Holand WN, Reid DD. The urban factor in chronic bronchitis. Lancet 1965; 1: 445-448.

8. Ferris BG, Higgins TT, Higgins MW, et al. Chronic nonspecific respiratory disease, Berlin, New Hampshire 1961 - 1967: a cross-sectional study. Am Rev Resp Dis 1971; 104: $232-244$

9. Love G, Shu Ping Lan, Smy C, et al. The incidence and severely of acute respiratory illness in families exposed to different levels of air pollution, New York Metropolitan Area, 1971-1972. Arch Environ Health 1981; 36: 66-74.

10. Burrows B, Kellogg AL L, Buskey S. Relationship of symptoms of chronic bronchitis and emphysema to matter and air pollution. Arch Environ Health 1968; 16: $406-413$.

11. Sawiki F. Chronic non-specific respiratory diseases in the city of Cracow. Statistical analyses of air pollution by suspended particulate matter and sulphur dioxide. Epidemiol Rev 1969; 23: 221-231.

12. Van der Lende R, Kok TJ, Peset Reig R, Quanjer PhT, Schouten JO, Orie NGM. Decreases in VC and FEV1 with time: indicators for effects of smoking and air pollution. Bull Eur Physiopathol Respir 1981; 17: $775-792$.

13. Aubry F, Gibbs GW, Beckake MR. Air pollution and 
health in three urban communities. Arch Environ Health 1979; 34: 360 - 367.

14. Bouhuys A, Beck GJ, Schoenberg JB. Do present levels of air pollution outdoors affect respiratory health? Nature 1978; 276: 466-471.

15. Antó JM, Vermiere P, Sunyer J. Epidemiology of Chronic Obstructive Pulmonary Diseases. Eur Respir Mon 2000; 15: 1-22.

16. Siafakas NM, Vermeire P, Pride NB, et al. on behalf of the Task Force. Optimal assessment and management of chronic obstructive pulmonary disease (COPD). Eur Respir J 1995; 8: 1398-1420.

17. Fletcher CM, Peto R, Tinker CM, Spizer FE. The Natural History of Chronic Bronchitis and Emphysema. Oxford University Press, Oxford, 1976.

18. Burrows B Natural history of chronic airflow obstruction. In: Hensley MJ., Saunders NA, eds. Clinical epidemiology of Chronic Obstructive Pulmonary Disease. New York, Marcel Dekker Inc., 1989; $99-$ 107.

19. Fletcher CM, Peto R. The natural history of chronic airflow limitation. BMJ 1977; 1: 1645-1648.

20. Annesi I, Kauffman F. Is respiratory mucus hypersecretion really an innocent disorder? Am Rev Respir Dis 1986; 134: 688-693.

21. Wolkove N, Dajczman E, Ccolacone A, Kreisman H. The relationship between pulmonary function and dyspnea in obstructive lung disease. Chest 1989; 96: $1247-1251$.

22. Twist JW, Staal BJ, Brinkkman MN, Kemper HC, van Mechelen W. Tracking of lung function parameters and the longitudinal relationship with lifestyle. Eur Respir J 1998; 12: 627-634.

23. Schwartz J, Dockery DW. Increased mortality in Philadelphia with daily air pollution concentrations. Am Rev Respir Dis 1992; 145: 600-604.

24. Schwartz J. What are people dying of on high air pollution days? Environ Res 1994; 64: 26-35.

25. Katsouyanni K, Karakatsani A, Messari I, et al. Air pollution and cause specific mortality in Athens. J Epidemiol Com Health 1990; 44: 321 - 324.

26. Katsouyanni K, Touloumi G, Spix C, et al. Shortterm effects of ambient sulphur dioxide and particulate matter on mortality in 12 European cities: results from the APHEA project. BMJ 1997; 314: $1658-$ 1663.

27. Zmirou D, Schwartz J, Saez M, et al. Time-series analysis of air pollution and cause-specific mortality. Epidemiology 1998; 9: 495-503.

28. Anderson HR, Spix C, Medina S, et al. Air pollution and daily admissions for chronic obstructive pulmonary disease in 6 European cities: results from the APHEA project. Eur Respir J 1997; 10: 1064-1071.

29. Schwartz J. Air pollution and hospital admissions for the elderly in Birmingham, Alabama. Am J Epidemiol 1994; 139: 589-598.

30. Schwartz J. Air pollution and hospital admissions for the elderly in Detroit, Michigan. Am J Respir Crit Care Med 1994; 150: 648-655.

31. Schwartz J. PM10, ozone, and hospital admissions for the elderly in Minneapolis-St Paul, Minnesota. Arch Environ Health 1994; 49: 366-374.

32. Burnett RT, Dales R, Krewski D, Vincent R, Dann T, Brook JR. Associations between ambient particulate sulfate and admissions to Ontario hospitals for cardiac and respiratory diseases. Am J Epidemiol 1995; 142: $15-22$.
33. Schwartz J. Air pollution and hospital admissions for respiratory disease. Epidemiology 1996; 7: 20-28.

34. Morgan G, Corbett S, Wlodarczyk J. Air pollution and hospital admissions in Sydney, Australia, 1990 to 1994. Am J Public Health 1998; 88: 1759 - 1760.

35. Schwartz J, Morris R. Air pollution and hospital admissions for cardiovascular disease in Detroit, Michigan. Am J Epidemiol 1995; 142: 23 - 35.

36. Schwartz J. Air pollution and hospital admissions for heart disease in eight U.S. counties. Epidemiology 1999; 10: 17-22.

37. Sunyer J, Schwartz J, Tobías A, Macfarlane D, Garcia J, Antó JM. Patients with chronic obstructive pulmonary disease are at increased risk of death associated with urban particle air pollution: a casecrossover analysis. Am J Epidemiol 2000; 151: 50-56.

38. Pope AC, Kanner RE. Acute effects of PM10 pollution on pulmonary function of smokers with mild to moderate chronic obstructive pulmonary disease. Am Rev Respir Dis 1993; 147: 1336-1340.

39. Dockery DW, Ware JH, Ferris BG, Speizer FE, Cook NR, Herman SM. Change in pulmonary function in children associated with air pollution episodes. $J$ Air Pollut Control Assoc 1982; 32: 937-942.

40. Dassen DW, Brunekreef B, Hoek G, et al. Decline in children's pulmonary function during an air pollution episode. J Air Pollut Control Assoc 1986; 36: 1123 1127.

41. Studnicka MJ, Frisher T, Meinert R, et al. Acidic particles and lung function in children. A summer camp study in the Austrian Alps. Am J Respir Crit Care Med 1995; 151: $423-430$.

42. Scarlett JF, Abbott KJ, Peacock JL, Strachan DP, Anderson HR. Acute effects of summer air pollution on respiratory function in primary school children in southern England. Thorax 1996; 51: 1109-1114.

43. Harré E, Price PD, Ayrey RB, Toop LJ, Martin IR, Town GI. Respiratory effects of air pollution in chronic obstructive pulmonary disease: a three month prospective study. Thorax 1997; 52: $1040-1044$.

44. Higgins BG, Francis HC, Yates CJ, et al. Effects of air pollution on symptoms and peak expiratory flow measurements in subjects with obstructive airways disease. Thorax 1995; 50: 149-155.

45. Zee SC, Hoek G, Boezen MH, Schouten JP, Wijnen $\mathrm{JH}$, Brunekreef B. Acute effects of air pollution on respiratory health of $50-70$ yr old adults. Eur Respir $J$ 2000; 15: 700-709.

46. Dockery DW, Pope CA, Xu X, et al. An association between air pollution and mortality in six US cities. $N$ Engl J Med 1993; 32: 1753 - 1759.

47. Pope CA, Thun MJ, Namboodiri MM, et al. Particulate air pollution as a predictor of mortality in a prospective study of US adults. Am J Respir Crit Care Med 1995; 151: 669-674.

48. Abbey DE, Mills PK, Petersen FF, Beeson WL. Longterm ambient concentrations of total suspended particulates and oxidants as related to incidence of chronic disease in California preadolescent children. Am Rev Respir Dis 1986; 133: 834-852.

49. Abbey DE, Nishino N, McDonell WF, et al. Longterm inhalable particles and other air pollutants related to mortality in non-smokers. Am J Respir Crit Care Med 1999; 159: 372-382.

50. Baldi L, Beurton-Aimar M, Tessier JF, Nejjari JF, Kauffman F. Effect of air pollution on long-term 
mortality: preliminary results of the French PAARC study. Eur Respir J 1997; 10: 228s-229s.

51. Hunt LW, Silverstein MD, Reed Ch E, et al. Accuracy of the death certificate in a population-based study. JAMA 1993; 269: 1947-1952.

52. Euler G, Abbey DE, Magie AR, Hodgkin J. Chronic obstructive pulmonary disease symptom effects of long-term cumulative exposure to ambient levels of total suspended particulates and sulfur dioxide in California Seventh-day Adventist residents. Arch Environ Health 1987; 42: $213-222$.

53. Zemp E, Elsasser S, Schindler C and the SAPALDIA team. Long-term ambient air pollution and respiratory symptoms in adults (SAPALDIA study). Am J Respir Crit Care Med 1999; 159: 1257-1266.

54. Schwartz J. Particulate air pollution and chronic respiratory disease. Environ Res 1993; 62: 7-13.

55. Portney PR, Mullahy J. Urban air quality and chronic respiratory disease. Regi Sci and Urb Econ 1990; 20: 407-418.

56. Bjornsson E, Plaschke P, Norrman E, et al. Symptoms related to asthma and chronic bronchitis in three areas of Sweden. Eur Respir J 1994; 7: 2146-2153.

57. Fosberg B, Stjernberg N, Wall S. Prevalence of respiratory and hyperreactivity symptoms in relations to levels of criteria air pollutants in Sweden. Eur J Public Health 1997; 7: 291 - 296.

58. Dockery DW, Speizer FE, Stram DO, Ware JH, Spengler JD, Ferris BG Jr. Effects of inhalable particles on respiratory health of children. Am Rev Respir Dis 1989; 139: 587-594.

59. Schwartz J. Lung function and chronic exposure to air pollution: a cross-sectional analysis of NHANES II. Environ Res 1989; 50: 309-321.

60. Stern BR, Raizenne ME, Burnett RT, Jones L, Kearney J, Franklin CA. Air pollution and childhood respiratory health: exposure to sulfate and ozone in 10 Canadian rural communities. Environ Res 1994; 66: $125-142$

61. Raizenne M, Neas LM, Damokosh AI, et al. Health effects of acid aerosols on North American children: pulmonary function. Environ Health Perspect 1996; 104: $506-514$.

62. Peters JM, Avol E, Gauderman J, et al. A study of twelve southern California communities with different levels and types of air pollution. Effects on pulmonary function. Am J Respir Crit Care Med 1999; 159: $768-$ 775 .

63. Ackermann-Liebrich U, Leuenberger P, Schwartz J, et al. and the SAPALDIA team. Lung function and long term exposure to air pollutants in Switzerland. Am J Respir Crit Care Med 1997; 155: 122-129.

64. Chesnut LG, Schwartz J, Savitz DA, Burchfiel CM. Pulmonary function and ambient particulate matter: epidemiological evidence from NHANES I. Arch Environ Health 1991; 46: 135-144.

65. Schindler Ch, Ackermann-Liebrich U, Leuenberger P, et al. and the SAPALDIA team. Associations between lung function and estimated average exposure to $\mathrm{NO}_{2}$ in eight areas of Switzerland. Epidemiology 1998; 9: $405-411$.

66. Abbey DE, Burchette RJ, Knutsen SF, McDonnell WF, Lebowitz MD, Enright PL. Long-term particulate and other air pollutants and lung function in nonsmokers. Am J Respir Crit Care Med 1998; 158: 289 298.

67. $\mathrm{Xu} \mathrm{XP,} \mathrm{Dockery} \mathrm{DW,} \mathrm{Wang} \mathrm{LH.} \mathrm{Effects} \mathrm{of} \mathrm{air}$ pollution on adult pulmonary function. Arch Environ Health 1991; 46: $198-206$.

68. Dodge R, Solomon P, Moyers J, Hayes C. A longitudinal study of children exposed to sulfur oxides. Am J Epidemiol 1985; 121: 720-736.

69. Frisher T, Studnicka M, Gartner Ch, et al. Lung function growth and ambient ozone. A three year population study in school children. Am J Respir Crit Care Med 1999; 160: 390-396.

70. Kopp MV, Bohnet W, Frisher T, et al. Effects of ambient ozone on lung function in children over a two-summer period. Eur Respir $J$ (in press).

71. Jedrychowski W, Flak E, Mroz E. The adverse effect of low levels of ambient air pollutants on lung function growth in preadolescent children. Environ Health Perspect 1999; 107: 669-674.

72. Detels R, Tashkin DP, Sayre JW, et al. The UCLA population studies of CORD: X. A cohort study of changes in respiratory function associated with chronic exposure to $\mathrm{SO}_{\mathrm{X}}, \mathrm{NO}_{\mathrm{X}}$, and hydrocarbons. Am J Public Health 1991; 81: 350-359.

73. Tashkin DP, Detels R, Simmons M, et al. The UCLA population studies of chronic obstructive respiratory disease: XI. Impact of air pollution and smoking on annual change in forced expiratory volume in one second. Am J Respir Crit Care Med 1994; 149: 1209 1217.

74. Anthonisen NR, Manfreda J, Warren CP, Hershfield ES, Harding GK, Nelson NA. Antibiotic therapy in exacerbations of chronic obstructive pulmonary disease. Ann Int Med 1987; 106: 196-204.

75. Rothman KJ, Greenland S. Modern epidemiology, 2nd Edition. Philadelphia, Lippincott-Raven, 1998; $44-45$.

76. Szklo M, Nieto FJ. Beyond the basics. Gaithesburg: An Aspen publication. Epidemiology 2000; 153-169.

77. Blakely T, Woodward AJ. Ecological effects in multilevel studies. J Epidemiol Com Health 2000; 54: 367 374.

78. Hatch M, Thomas D. Measurement issues in environmental epidemiology. Environ Health Perspect 1993; 101: Suppl. 4. 49-57.

79. Künzli N, Ackermann-Liebrich U, Brandli O, Tschopp JM, Schindler C, Leuenberger $\mathrm{P}$ and SAPALDIA team. Clinically "small" effects of air pollution on FVC have a large public heath impact. Eur Respir J 2000; 15: 131-136. 